\title{
ALUNO DO CURSO NOTURNO (19 GRAU): UM ESTUDO DE SUA IDENTIDADE SOCIAL E DE SEU AUTO-CONCEITO
}

\author{
MARY NEIDE DAMICO FIGUEIRÓ1 \\ Dra. MARIA ALICE VANZOLINI DA SILVA LEME 2
} FIGUEIRÓ, M.N.D.: LEME, M.A. da S. Aluno do curso noturno (19 grau): um estudo de sua identidade social e de seu
auto-conceito. Semina: Ci. Soc./Hum., Londrina, v. 13, n. 3,p. 173-179, set. 1992 .

RESUNO: O presente trabalho teve como principal objetivo investigar a identidade social de alunos de curso notumo e identifcar os elementos dessa identidade que fazem parte do auto-conceito desses estudantes. Como sujeitos, foram selecionados estudantes de dois colégios estaduais de um municipio do Norte do Paraná. Fez-se uso do procedimento experimental - que elucida os conteúdos do auto-conceito - desenvolvido por Zavalbni, selecionandb-se para isso dois grupos de sujeitos: dezesseis estudantes do curso notumo e dezesseis do diumo. Cada elemento teve como tarefa atribuir caracteristicas para seu ingroup" e para o "out-group", apontando as que fazem parte de seu auto-conceito. Ficou evidenciada a diferença entre "Nós" $e$ "Eles"; cada membro, peb processo de comparaçăo, avaliou "Nós" mais positivamente que "Eles" $\theta$ atribuiu ao seu auto-conceito um número maior de caracteristicas positivas que negativas. A característica essencial presente na identidade social e no auto-conceito do aluno notumo foi: "interesse pelo estudo", em funçăo de ver nole um moio de "subir na vida". Os dados encontrados confirmam a necessidade da comparaçấo entre grupos para a formaçăo da identidade social e o papel dessa na formaçăo do auto-conceita.

PALAVRAS-CHAVE: Curso-notumo de $1^{\circ} \mathrm{grau}$; Aluno do notumo; Identidade social; Auto-conceito

\section{1 - INTRODUÇĀO}

\section{1 - Curso noturno de $1^{9}$ grau}

Estudos realizados na década de oitenta mostram que as dificuldades continuamente apontadas com relaçăo ao ensino brasileiro encontram-se exacerbadas quando se trata do ensino noturno.

TENCA (1982), ao discutir especificamente sobre os alunos do curso noturno de ensino da rede pública estadual paulista de $1^{\circ}$ grau, analisa alguns fatores responsáveis pelos altos Indices de repetência e evasão e denúncia a deficiente escolarização dos que trabalham.

Essa deficiência é denunciada também em outras publicaçóes, entre elas: ALMEIDA (1988), que discorre sobre a história e os problemas do ensino noturno do Estado de São Paulo; SILVA \& NOGUEIRA (1984), cuja refle- xẫo culminou na publicação do livro intitulado: "A escola pública e o desafío do curso noturno"; CARVALHO (1982), cujo trabalho consistiu em um estudo de caso de uma escola noturna de $1^{\circ}$ grau da cidade de Ribeirăo Preto, estado de São Paulo. Desse último trabalho resultou também a publicação de um livro: "Ensino noturno: realidade e ilusåo" (CARVALHO, 1987).

Propostas para melhorar a qualidade do ensino noturno săo encontradas por exemplo, no texto de ALMEIDA (1988) e no de CARVALHO (1982). O primeiro ressalta as propostas resultantes do Dia Nacional de Debate sobre Educação (18 de setembro de 1985) e o segundo inclui sugestöes levantadas junto aos próprios estudantes de curso noturno.

Apesar de a maioria das publicaçöes estar voltada para a realidade do Estado de São Paulo, 6 possivel crer que as críticas e sugestóes apontadas possam ser extra-

1 - Departamento de Psicologia Social e Institucional da Universidade Estadual de Londrina, Caixa Postal 6001, CEP 86051-970, Londrine - Paraná - Brasil, Mestranda em Psicologia Escolar da USP.

2 - Departamento de Psicologia Experimental da USP. 
poladas para as escolas noturnas brasileiras.

No entanto, faz-se necessário um número maior de estudos sobre o ensino noturno de $1^{\circ} \mathrm{grau}$, com o objetivo de conhecer mais profundamente essa realidade especifica.

ALMEIDA (1988) demonstra preocupação com o pequeno número de estudos nessa órea, apresentando uma listagem das pesquisas a artigos publicados. Uma vez que o primeiro ftem dessa listagem data de 1979, depreende-se que a preocupação com essa questão é recente.

Dentre o parco número de publicaçóes cientificas, destaca-se a composição integral de um periódico pelo agrupamento de vários textos referentes ao ensino noturno de $1^{\circ}$ e $2^{\circ}$ grau (O Ensino noturno, 1986).

No texto de TENCA (1982), como no de CARVALHO (1982), encontra-se a afirmação de que, embora o Estado mantenha cursos para atender aos estudantes que precisam trabalhar durante o dia, o curso oferecido năo atende aos interesses e possibilidades dos alunos.

A grande maioria desses alunos têm esperança na educaçăo e vêem nela um meio de subir na vida. Além disto, percebern os professores como sendo condescendentes face d̀s exigências pedagógicas - dão pouca matêria e não dão lição para casa (SILVA, 1984; CARVALHO, 1982).

Segundo TENCA (1982), esses alunos percebem o ensino como sendo "mais fraco" e "resumido" à noite. Por sua vez, salienta essa autora, a grande parte dos diretores entrevistados percebe de maneira negativa os estudantes de noturno de $1^{\circ} \mathrm{grau}$, culpando-os pelo mau desempenho escolar e classificando-os como rebeldes, marginais e outros adjetivos depreciativos. Afirmam que os alunos do noturno produzem menos e são apáticos e desinteressados pelos conteúdos escolares.

Essa percepção dos diretores (bem como a dos professores) pode ter uma influência negativa sobre a interação desses profissionais com os estudantes e consequentemente, sobre o desenvolvimento escolar desses últimos.

Mais estudos devem ser realizados para buscar conhecer esses estudantes, aprofundando ainda mais na percepçăo que eles têm, nảo apenas do ensino, mas especialmente de si próprios e do grupo ao qual pertencem.

É propicio neste momento retomar para reflexão a proposiçāo de SILVA \& NOGUEIRA (1984) de que: "a problemática do ensino noturno deve ser encarada como o principal desafio para a democratizaçāo da escola".

\section{2 - A teoria da identidade social}

A formaçáo do auto-conceito de um indivlduo é complexa e envolve, além da identidade pessoal, a identidade social. Essa última é considerada como a "parcela do auto-conceito de um individuo que deriva do seu conhecimento da sua pertença a um grupo (ou grupos) social, juntamente com o significado emocional e de valor associado dquela pertença* (TAJFEL, 1984, p. 290).
A partir pois, da formaçảo no indivíduo do sentimento de pertença a um grupo, ele passa a assumir para si as caracteristicas desse grupo.

Segundo a Teoria da Identidade Social de TAJFEL (1984), os elementos do grupo psicológico ("in-group") percebem-se como uma identidade distinta, avaliando-se mais frequentemente de forma positiva que a avaliaçăo que fazem dos elementos do outro grupo, do qual não fazem parte ("out-group").

Isto se deve necessidade que todo o individuo tem de ter um auto-conceito positivo e consequentemente de pertencer a um grupo que contribua, de alguma maneira, para os aspectos positivos de sua identidade social.

Quando os elementos que compōem o grupo percebem que possuem caracterlsticas comuns, emerge af um grupo psicológico e qualquer avaliaçăo que o individuo venha a fazer desse seu grupo de pertença se fundamenta na comparação com outro (ou outros) grupo ("out-group").

O objetivo do presente trabalho consistiu em: - investigar que elementos constituem a identidade social dos alunos de $1^{\circ}$ grau de escolas públicas estaduais, tanto no curso noturno, como no diurno; - verificar quais desses elementos são considerados como fazendo parte do auto-conceito; - contribuir para o enfrentamento da problemática do ensino noturno.

\section{2 - METODOLOGIA}

\section{1 - Sujeitos}

Grupo A: composto por 16 estudantes do curso noturno, sendo 8 do sexo masculino e 8 do femínino, variando de 13 a 20 anos, pertencentes às $5^{a}, 6^{a}, 7^{a}$ e $8^{a}$ séries do $19 \mathrm{grau}$.

Foi usado como critério de seleção, que cada participante já tivesse estudado um ano no curso noturno, excetuando-se o presente ano - forçosamente todos os estudantes do noturno estudaram anteriormente no perlodo diurno, uma vez que as $1^{\mathrm{a}} \mathrm{s}, 2^{\mathrm{a}} \mathrm{s}, 3^{\mathrm{a}} \mathrm{s}$ e $4^{\mathrm{a}} \mathrm{s}$ séries só funcionam nesse perlodo.

Grupo B: composto por 16 estudantes do curso diurno (vespertino), sendo 8 do sexo masculino e 8 do feminino, variando de 12 a 16 anos, pertencentes à $7^{\text {a }}$ série do $1^{\circ} \mathrm{grau}$.

O estudo foi realizado com estudantes de dois colegios estaduais de um municfpio do Norte do Paraná, localizados em bairros da periferia da cidade, onde a população é de baixa renda.

A principio pretendia-se selecionar alunos com idade variando de 13 a 16 anos. Como no diurno essa faixa etária frequentava a $7^{\text {a }}$ série, decidiu-se por concentrarse nessa série; porém, no noturno, foi necessário incluir alunos de outras séries, alêm da 7a mite estipulado de idade; assim mesmo, foi preciso incluir alguns alunos com idade um pouco acima de 16 anos. 


\section{2 - Procedimento Experimental}

O presente trabalho foi realizado no primeiro semestre de 1991 e baseou-se no procedimento experimental desenvolvido por ZAVALLONI (1973) para elucidar os conteúdos do auto-conceito, onde as técnicas usadas são: Técnica de Introspecção Focalizada e Análise do Conteúdo.

Foi realizado inicialmente um estudo piloto com uma amostra de 4 estudantes do noturno e 4 do diurno, para teste do procedimento e para verificar se as categorias noturno/diurno produziam percepçōes de filiação diferenciadas.

Constatada a eficácia dessa categorização, deu-se início aos passos propostos por ZAVALLONI (1973), de acordo com a Técnica de Introspecção Focalizada em Vârios Estágios.

Os alunos foram entrevistados individualmente, variando de vinte a trinta minutos cada entrevista, tendo sido todas elas gravadas. Além dos dados de identificação, era pedido a cada um que completasse com cinco caracterlsticas a frase: "Nós os estudantes do noturno somos..." (no caso dos estudantes do diurno, a frase era: "Nós os estudantes do diurno somos...").

De acordo com o estabelecido para o estágio 1 da técnica supra-citada, era perguntado se cada um dos atributos que deu ao seu próprio grupo se aplica também a si próprio e se é muito aplicável (M.A.) a si próprio, pouco (P.A.), ou nada aplicável (N.A.). Era solicitado que desse a valência de cada atributo: positivo, negativo ou neutro.

Passando-se para o estágio 2 - onde pretendia-se investigar os limites do grupo - eram feitas as perguntas:

a) $O$ atributo se refere ao grupo como um todo ou a um sub-grupo especifico?

b) Está dando sua visão pessoal ou de alguma outra pessoa?

Em prosseguimento, no estágio 3 era perguntado a cada sujeito sobre o significado e a implicação de cada atributo quando ele era usado para descrever o grupo e quando ele era usado para descrever a si mesmo.

Imiciando-se a segunda parte da entrevista, a cada estudante era pedido que completasse com cinco atributos a frase: "Eles os alunos do __ são..." (neste momento, inseria-se na lacuna dessa frase a palavra diurno para os alunos do noturno e a palavra noturno, para os do diurno).

De forma análoga, nesta segunda parte eram a seguir feitas as mesmas perguntas pertinentes aos estágios 1, 2 e 3 da Técnica de Introspecçāo Focalizada em Vários Estágios.

\section{3 - RESUltAdos e discusSÃo}

\section{No Estágio 1}

Como se verifica na Fig. 1, "Nos"” produziu uma grande maioria de atributos positivos, tanto entre estudantes do noturno que designaram para seu "ingroup" 75,9\%, como entre os do diurno, que designaram $70.0 \%$ de positivo também para seu próprio "in-grupo".

Já a percentagem de adjetivos positivos eliciados por "Eles" caiu para $43.4 \%$ entre os primeiros e $52.5 \%$ para os segundos.

Quanto aos atributos negativos, os estudantes do noturno designaram $17.7 \%$ para seu "in-group" e de forma semelhante, os do diurno designaram $17.5 \%$ para seu "in-group".

Já a percentagem de adjetivos negativos eliciados por "Eles" aumentou, atingindo $47,8 \%$ para os primeiros e $34,6 \%$ para os segundos.

É posslvel então constatar que os sujeitos de ambos os grupos avaliaram positivamente seu "in group", numa proporção significativamente maior, o que é coerente com a já explicitada Teoria da Identidade Social de Tajfel.

De acordo com a Fig. 1, os do noturno avaliaram de forma equilibrada os do diurno $(43.4 \%$ de positivo e $47.8 \%$ de negativol, enquanto que esses últimos avaliaram os do noturno, numa proporção um pouco maior de

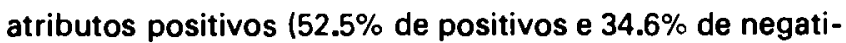
vos).

É provável que a razão pela qual o número dos atributos negativos não ultrapassasse (ou ultrapassasse levemente como na primeira situação) o dos positivos, seja o fato de que, apesar de formarem sub-categorias diferentes (diurno-noturno) ambos os grupos têm em comum a categoria "estudante".

De acordo com a Fig. 2, a percentagem dos atributos auto-aplicáveis foi bastante alta quando se tratava dos atributos do seu respectivo "in-group": $65.8 \%$ M.A. (muito aplicável a si próprio) para os do noturno e $60.7 \%$ M.A. (muito aplicável a si próprio) para os do diurno. Por outro lado, a percentagem dos atributos autoaplicáveis caiu acentuadamente quando se tratava dos atributos do "out-group": $31.4 \%$ M.A. no noturno e $37.9 \%$ M.A. no diurno.

Congruentemente com os resultados acima, a percentagem dos atributos nada aplicáveis a si próprios (N.A.) deu-se da seguinte forma.

- noturnos: $12.6 \%$ N.A. das características do seu "in-group", contra $54.2 \%$ N.A. das do "out-group;

- diurnos: $8.8 \%$ N.A. de seu "in-group", contra $34.1 \%$ N.A. do "out-group".

Esses dados demonstram a existência do sentimento de pertença ao seu "in-group", em ambos os grupos.

Isso nos leva a crer que o critério usado para selecionar alunos do noturno para este trabalho (que os mesmos já tivessem frequentado um ano de curso noturno, excetuando-se o presente ano) pareceu relevante para tentar garantir que já tenha sido possível o esvanecimento do sentimento de pertença ao grupo do diurno e concomitantemente, $o$ fortalecimento de um sentido de pertença ao grupo do noturno. 


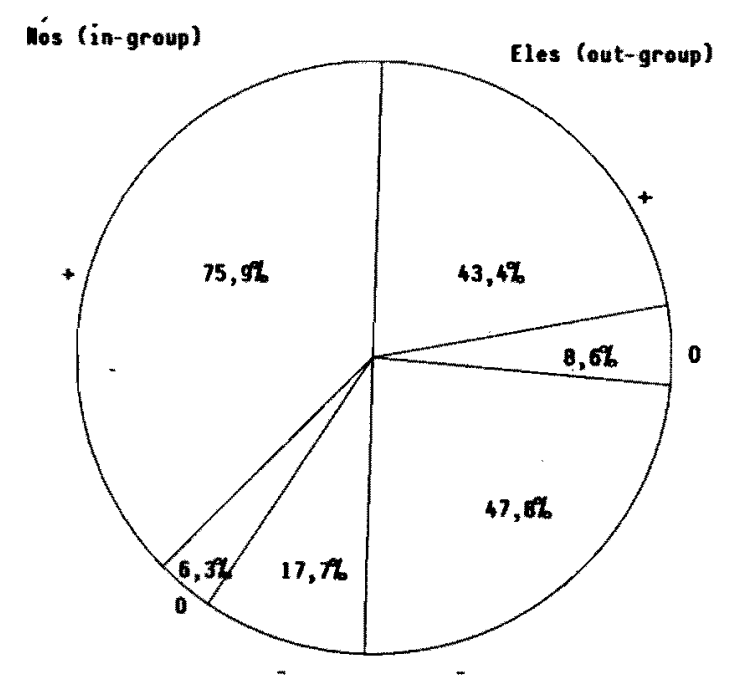

1001

$100 \mathrm{th}$

(79 resp.) (69 resp.)

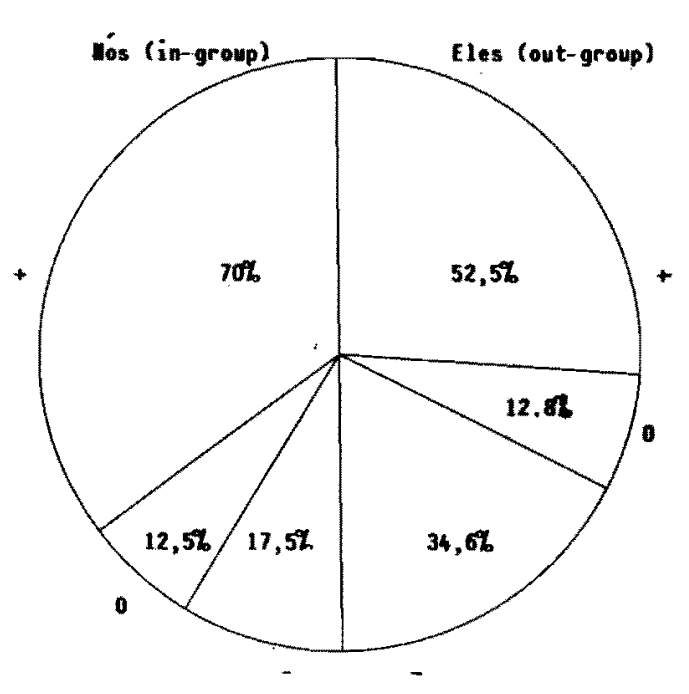

$100 \% \quad 100 \%$

(80 resp.) (78 resp.)

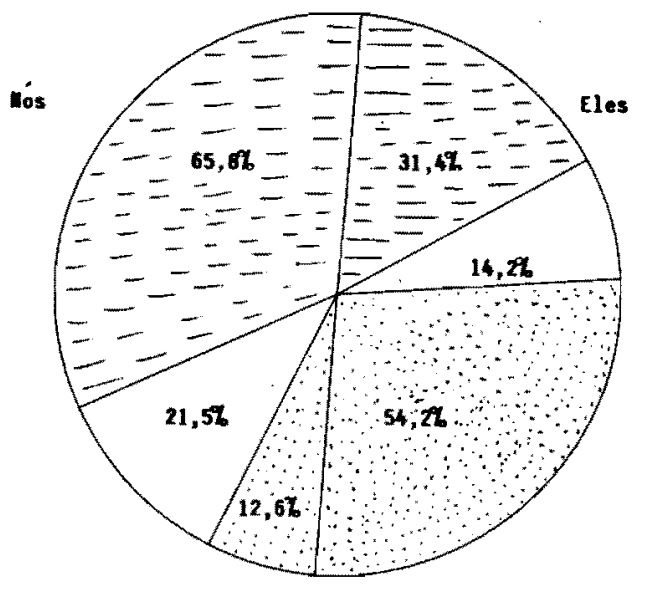

$100 \%$

$100 \mathrm{~h}$

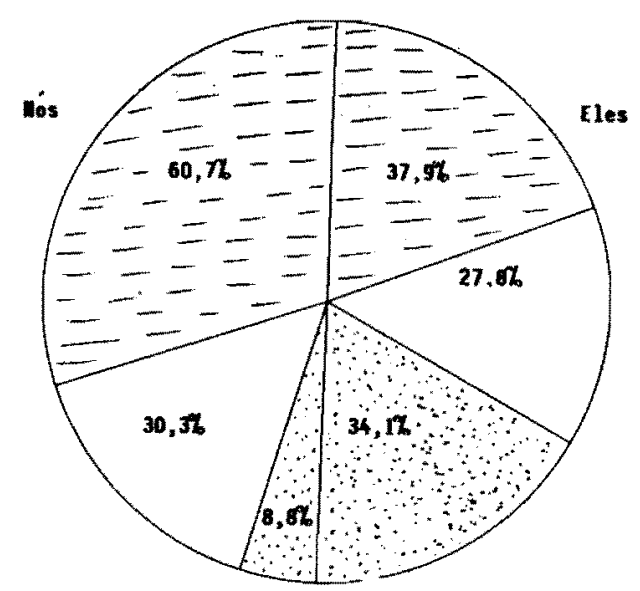

$1002 \quad 100 t$ 
NOTURNO

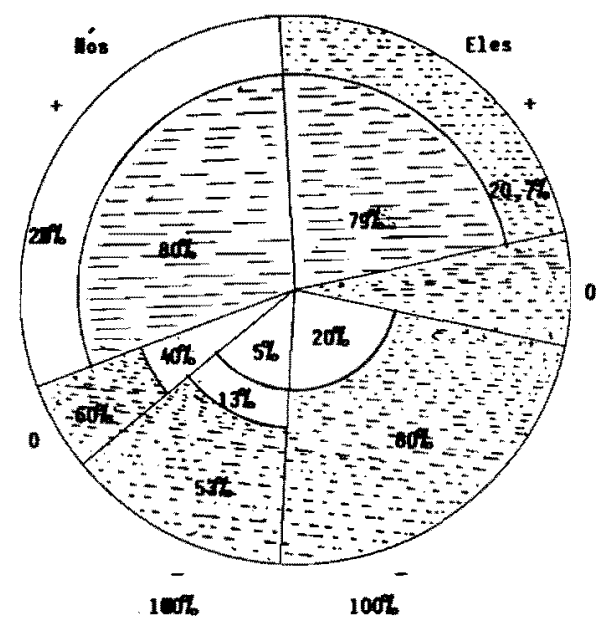

DIURNO

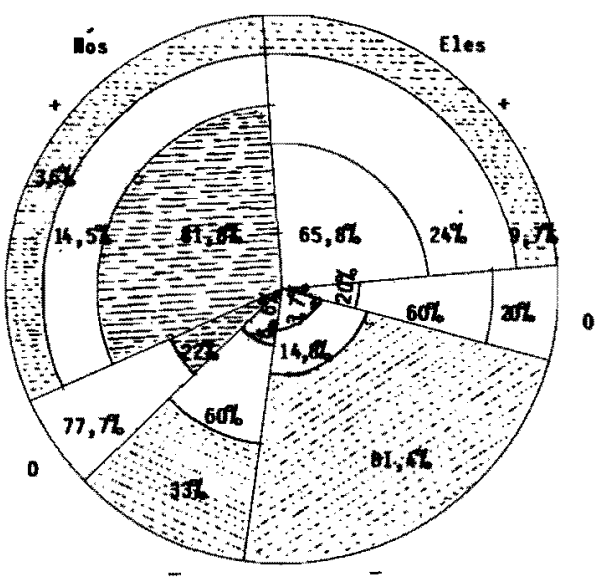

Ah - Muito aplicivel a si próprio

P.l. - Pouco aplicavel a si proprio

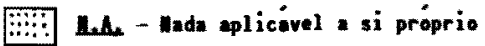

\section{FIGURA 3 - AUTO-APLICABILIDADE E VALÊNCIA DE ATRIBUTOS}

$\mathrm{Na}$ figura 3 verifica-se que a maior percentagem de atributos identificados como próprios tendem a estar localizados na seçăo de "Nós"-positivo. Assim, os do noturno consideraram $80.0 \%$ M.A. a si próprios os atributos positivos do seu "in-group", contra 5.0\% M.A. a si próprio dos atributos negativos.

Do mesmo modo, os do diurno consideraram $81.8 \%$ M.A. a si próprios os atributos positivos do seu "in-group", contra 3.6\% M.A. a si próprios, dos atributos negativos do seu "in-group".

Essa alta percentagem de muita aplicabilidade (M.A.) a si próprio, dentro dos atributos positivos, é coerente com a posição de Tajfel, de que os individuos têm necessidade de auto-imagem positiva e que o auto-conceito 6 influenciado pela Identidade Social.

A necessidade de uma auto-imagem positiva, de que nos fala esse autor, é claramente comprovada quando nos deparamos com o seguinte exemplo: um sujeito do noturno, ao dizer qual era o grupo de referéncia enquanto pensava em "Nós os estudantes do noturno somos...", afirmou: "pensei numa classe de $\mathbf{8}^{\mathrm{a}}$ série, não a minha, mas uma outra que é melhor". Esse sujeito deu quatro caracteristicas positivas para "Nós", classificando essas como M.A. (muito aplicável) a si próprio e uma neutra, classificando essa como P.A. (pouco aplicável a si próprio).

\section{No Estágio 2}

"Nós os..." evocou, na maioria dos sujeitos, a própria classe, ou seja, enquanto tentavam atribuir ca- racterísticas para seu próprio grupo, a maioria dos sujeitos, tanto do diurno, como do noturno, diziam estar pensando em sua própria classe.

"Eles 0s..." evocou com mais frequência, para os sujeitos do diurno, um grupo mais amplo de alunos indiferenciados (como se fosse uma grande massa). Exemplo: "Pensei em todos os estudantes do noturno, de forma geral.

"Eles os..." evocou com mais frequencia, para os do noturno, pequenos grupos de pessoas conhecidas. Por exemplo: "Pensei em uma amiga"; "Pensei em uns três ou quatro alunos que eu conheço e que estudam durante o dia"; "Pensei em algumas pessoas conhecidas"; "Pensei nos alunos que estudam de dia, no meu colégio".

Quando foram interrogados, conforme a queståo b do estágio 2, sobre se estavam dando sua visáo pessoal ou de alguma outra pessoa, apenas uma aluna do noturno disse que estava se baseando na fala de uma amiga sua sobre um grupo de alunas do diurno, ao definir esse último grupo; o restante disse estar dando sua visăo pessoal.

\section{No Estágio 3}

Năo foi registrada nenhuma mudança na conotaçåo dos atributos, quando eles eram referidos ao grupo ou a si próprio.

A Anślise do Conteúdo - a outra técnica que integra a procedimento proposto por ZAVALLONI (1973) leva-nos a vários resultados que a seguir são delineados.

Das caracter/sticas negativas atribuidas pelos 
estudantes do noturno ao próprio grupo ("Nós os alunos do noturno somos..."l, $42 \%$ são em funçăo do contexto escolar que, segundo sua percepção, defícitário. Por exemplo: "Nós somos mais diffceis de aprender... por causa do horário, do cansaço"; "Nós somos revoltados... devido ao cansaço trazido pelo trabalho e às preocupaçōes".

Em contrapartida, as caracterlsticas negativas atribuldas ao seu próprio grupo pelos estudantes do diurno sāo todas relacionadas aos próprios comportamentos. Por exemplo: "somos bagunceiros. porque conversamos durante a aula": "somos mal educados... porque não respeitamos os professores".

No que diz respeito à percepção de características negativas dadas para o "out-group", hâ significativos pontos em comum. Os do noturno atribuem para o "out-group" as seguintes caracteristicas; bagunceiros, mal educados e pouco interessados em aprender, enquanto que os do diurno atribuem para o seu "outgroup" as seguintes: bagunceiros, mal educados e briguentos.

Com respeito a atributos positivos designados com maior frequéncia, foi encontrado que o grupo do noturno se define mais como sendo bastante "interessado no estudo" (dos dezesseis entrevistados, quatorze definiram-se assim). De acordo com a verbalização desses estudantes, vêem no estudo "um meio de subir na vida".

Já os estudantes do diurno definiram mais positivamente a si próprios como sendo "bons alunos", "bons estudantes" - no sentido de cumpridores do dever; dos dezesseis alunos, treze atribulram a "Nós" essa característica.

\section{4 - CONCLUSÃo}

Tanto em relaçāo aos estudantes do noturno como aos do diurno, ficou evidenciada a necessidade que os indivlduos têm de se contrapor a um outro grupo ("Eles" ou "out-group") para poder avaliar a identidade do seu próprio grupo ("Nós" ou "in-group"); assim, avaliando mais positivamente "Nós" em oposiçăo a "Eles", 0 individuo mantém positivo seu auto-conceito.

Isso vem corroborar o papel da identidade social - juntamente com a pessoal - como fundamental para a formaçāo do auto-conceito.
Quer nos parecer que ver no estudo um meio de subir na vida é inerente á maioria dos estudantes de 1 ? grau noturno, uma vez que essa característica foi também encontrada por CARVALHO (1982) e SILVA \& NOGUEIRA (1984) em suas pesquisas.

Segundo os resultados deste presente trabalho, "ver no estudo um meio de subir na vida" é uma característica que aparece consequentemente aliada ao principal elemento da identidade social dos estudantes do noturno, qual seja: "ser interessado no estudo".

Por sua vez, essa última caracterlsticas apresentase mais acentuada nos momentos em que esses estudantes atribuem aos do diurno a caracterlstica de "pouco interessados no estudo".

Quanto aos do diurno, de acordo com este trabaIho, o principal elemento de sua identidade social se refere a: "ser bons estudantes" - no sentido de cumpridores do dever.

Isto nos faz crer que os estudantes do noturno, participantes desta pesquisa, parecem demonstrar um nlvel mais alto de conscientização do papel de estudantes.

Bastante significativo é o fato de que, enquanto os alunos do diurno associam suas caracteristicas negativas aos seus próprios comportamentos, os do noturno associam as suas ao contexto escolar.

Constatou-se que, segundo a opiniảo dos próprios alunos do noturno, seus potenciaiș de estudantes nảo vêm sendo explorados suficientemente. A grande maioria desses estudantes diz que o perfodo diurno é de melhor qualidade que o do noturno. Neste sentido, fica evidenciada a fala de um dos alunos: " ... gostaria de estudar de dia; o diurno é de maior qualidade; à noite o estudo é fraco, dâ pouco conhecimento".

Por outro lado, os do diurno nada afirmaram em relaçāo à qualidade do ensino, nem apresentaram tampouco comparaçōes entre a qualidade do ensino noturno e diurno.

Apesar de considerarem positivo o fato de os professores serem condescendentes em relaçäo às exigências pedagógicas, quinze dos dezesseis alunos do grupo noturno vêem isso como um fator que afeta a qualidade do ensino.

Medidas alternativas que visem a melhoria desse contexto, com ênfase especial na qualidade do ensino e a explorą̧ăo ainda maior do potencial desses estudantes. sāo medidas mandatficias para que não se delapide um capital humano altamente promissor. 
FIGUEIRO, M.N.D.; LEME, M.A.V. da S. Night-school students ( $1^{\circ}$ state): a study of his/her social identity and of his/her self-concept. Semina: Ci. Soc JHum., Londrina, v. 13, n. 3, p. 173-179, Sept. 1992.

ABSTRACT: This work was meant to investigate the social identity of night-school students and to establish which elements of such an identity are part of their self-concept. Some students from two state schools in a city in the North of Parana were selected as subjects. The experimental procedure, which explains the contents of self-concept and was developed by Zavalkni, was used in this work. Sixteen night-school students and sixteen day-time students were selected as subject-groups. Each member of these two groups was supposed to establish charactenstics for his/her in-group and out-group and point out those which were part of his/her own self-concept. The difference between "We" and "They" was outstanding. Each subject, by means of comparison, rated "We" more positively than "They" and presented more positive than negative characteristics for his/her own self-concept. The prevailing and essential characteristic for the social identy and self-concept of the night-school student was "interested in studying", for s/he sees it as a "way for social advancement". The data support the need for comparison between the groups in order to form their social identity and also support the role of this identity in the formation of self-concept.

KEY-WORDS: First grade night-school course; Night school students; Social identity; Self-concept.

\section{REFERÊNCIAS BIBLIOGRÁFICAS}

ALMEIDA, Laurinda Ramalho. O ensino noturno no estado de Sto Paulo: um pouco de sua histórla de seus problemas. Caderno de Pesquisa, Săo Paulo, n. 66, p. 49-62, ago, 1988.

Carvalho, Calla Pezzolo de. Ensino notuma: realidade e llusto. Slo Paulo: Cortez, 1987.

A questlo do ensino noturno. Educaça e Sociedade, Stio Paulo, v. 4, n. 13, dez. 1982.

O ENSINO noturno: conqulata, problema ou soluçăo? Cadernos CEDES, SEO Paulo, n. 16, 1986.

SILVA, Marla Tereza Rosembauer; NoGUEIRA, Madza Julita. A escola publica e o desafio do curso notumo. Săo Paulo: Cortez, 1984.
TAJFEL, H. Grupos humanos e categoria sociais - 1. [s. I.], Livros Horkontes, 1983.

TENCA, Suell Cotrim. Cursos noturnos: a pobre escolarbaço dos que trabalham. Cademos de Pesquisa, Sao Paulo, n. 43, p. 37-41, nov. 1982.

TURNER, John C. Social Identification and psychologlcal group formation. In: TAJFEL, H. The social dimension Cambridge: Unversity Press, 1984, v. 2.

ZAVALLON, Marlsa. Subjettve culture, self-concept and the social environment. International Journal of Psychology, Amsterdam, v. 8, n. 3, p. 183-192, 1973.

Recebido para publicaçăo em 4/11/92 